\title{
Leadership fostering via teaching business case studies: opportunities and limitations
}

\author{
Manuela Tvaronavičienè \\ Vilnius Gediminas Technical University \\ Saulètekio 11, LT-10223 \\ Vilnius \\ Lithuania
}

\begin{abstract}
In a contemporary complex environment, sustainable development of SMEs and large companies considerably depends on effective and efficient leadership. Fostering of business leadership abilities at contemporary universities could not be imagined and designed without application of case study teaching techniques.

This paper is devoted to the case studies teaching peculiarities and their implementation in the teaching process. At first, the format of a business case study suitable for fostering leadership abilities is discussed. Second, business case studies teaching techniques are presented, and the opportunities of leadership development are provided. Insights about case studies limitations and their reasons are formulated in order to shape up the picture. The author relies on over 10 years of business case studies-based teaching experience that can be used in studying leadership.
\end{abstract}

\section{Introduction}

A lot of definitions of leadership could be found in scientific and popular literature and discussion on leadership styles and their impact is on-going. In this paper we are not going to get into this discussion. On contrary, we base our investigation on very basic assumption that leadership as phenomenon, is ability to make decisions and to lead people towards implementations of set goals. In order to lead people, the leader has to be educated and responsible, otherwise leadership traits can have disastrous consequences.

In this paper we pose a question about possibility to develop ability to make rational decisions trough analysis of business cases. We tackle particularly business and management students who study at university, and, are supposed to lead businesses in the future. So, one can wonder when the analysis of business cases can facilitate development of ability to make right decisions, and what/when one can encounter limitations of the used case study method.

The insights provided is this paper are based on more than 10 years teaching of application of case study method for teaching. Responses of students, observations of professor and overall satisfaction by year by year achieved results will be generalized in this paper.

The paper is structured as follows: the first part will be devoted by description of a case study and teaching methodology in order to avoid misunderstanding what is being meant by a case study and describe very clearly adopted approach towards its use. The second part will be devoted to observations of opportunities of leadership development provided by this teaching method, and the final part will outline limitations of this method. We believe that the finalizing part is the most valuable one, since clear description of limitations would allow, as we believe, to avoid mistakes and increase efficiency of leadership traits development a whole.

\section{Format of a business case study, suitable for fostering of leadership abilities}

Inclinations, traits and abilities of students are discussed rather widely in the most recent scientific business literature (e.g. Naushad 2018; Bogdanović et al. 2018). This increasing attention to students are understandable; the context of aging societies, complexity of environment and increasing importance of sustainable entrepreneurship shifts the emphasis on development of new generation of leaders, which were able to set correct goals, and implement them efficiently in vide variety of situations and equipped with enormous flows of information including the big data on the job markets of the future (Strielkowski and Rausser 2013; Koudelková and Svobodová 2014; Kalyugina et al. 2015; Čábelková et al. 2015; Strielkowski et al. 2016; Zielińska 2016; Durglishvili 2017; Orlova et al. 2018; Plenkina et al. 2018; Ragulina et al. 2018; Naushad et al. 2018; Białowąs 2018; Shvetsova et al. 2018; Strielkowski 2018; Mikhaylov 2018; Kubeš and Rančák 2018, Tvaronavičienè 2018).

The enhanced attention to students respectively makes a question of their teaching techniques increasingly topical. Despite there is almost unanimous agreement that case studies are powerful tool of 
business education, there still rather different opinions could be encountered about what business case should look like and what techniques of its teaching could be used, what results are to be expected. Therefore, let us specify what we understand under business case and describe the approach and expected outcomes of its teaching.

Relevant business case study, which could, to our mind, be recommended for teaching purposes has to meet specific requirements. Let us go through those requirements, since content of a business case used for teaching is strongly related to its ultimate impact on students' abilities' development. Hence, we believe that the case study has to be based on real situation, which occurred in real company under real circumstances. Here we would argue with opponents, who believe that devised situation could serve as business case for teaching purposes. Real situation, of course, written for teaching purposes is more convincing, sometimes unexpected, and, in some cases can have continuation, which provides opportunity to examine what decision were made by real managers of company-protagonist. We completely agree that "compared to other methods, the strength of the case study method is its ability to examine, in-depth, a "case" within its "real-life" context (Yin 2006). Therefore, when simulated examples are used for lecturing purposes they shouldn't be called "case studies".

The second feature of a good business case is its layout. Business case should be finished at a certain point, where an important decision has to be made by a company's CEO. The decision, which address a problem, which has to be solved by the considered company. It is peculiar that by making decision the CEO usually has variety of alternative choices. Choosing of the most beneficial for a company option requires all the spectrum of skills and abilities, which are needed for decision making, i.e. understanding of causes of the problem and consequences, if one or another decision would be opted. Let us take a closer look at the process of decision-making, which has to be outcome of analysis of any case study.

\section{Opportunities of leadership development provided by application of case study teaching method: insights to limitations}

Let us look at the rather universal scheme of a business case analysis. After discussing the sequence and logic of teaching, we will indicate how, and at which stage of teaching process leadership skills of students are being fostered. A selected business case has to be given to students in advance, at least one day before the business case teaching, in order students had possibility to read it carefully in order to understand the situation. Usually, guiding questions at very end of the case study are being provided. It is very bad, if students arrive to business case teaching lecture without preparation. Actually, such students should not be allowed to participate in case study analysis. In current conditions of aging society, when young population becomes a minority group, and students transform into clients of university's fight with unprepared students become a challenge for a professor, who has to balance between quality standards and pleasing "students-clients". This externality may affect quality of business case teaching method, in case professor for one or other reasons is forced to allow unprepared students to participate in a lecture. Let us allow, that this is not the case, therefore further let us concentrate on "ideal" business case teaching conditions. At the beginning of the lecture students are assigned into groups, desirable, not more than 6 students in one group. In those groups students have to share their responses to questions provided at the end of assigned case, and develop discussion basing on opinions expressed by members of the group. Case study analysis session should start after students had their own discussions in groups. A professor starts case study analysis from posing a question about problems which could be found in the company in question. Here, one needs to draw attention to the logic on which the whole process of case study is being based: since a problem occurred, where unordinary decision has to be made by CEO, most likely the company itself has some problems, which has to be solved internally. In order to clarify what is being meant by problems, "which has to be solved internally", let us provide some examples. Hence, there could be problems related e.g. with company's organizational culture, when employees "jump" over layers of hierarchy in order to achieve their personal goals; organizational values, when declared values do not match behavioral patterns (e.g. Al-Kahtani 2018), organizational structure, when functions are duplicated; organizational culture, motivation system etc. Set of another type of problems could be related to company's strategy formulation issues, e.g. when more lucrative but more risky strategies have to be balance with more stable and better-known strategies, which generate lower value added. Human resources' management style, e.g. working in teams, and team appreciation versus individual achievement appreciation as well could be contentious choice for different companies. The examples provided allow to perceive how deep students are encouraged to dig in order to find solution for conflicts which arise among employees, sometimes among employees and administration, among companies and clients, or for example among subsidiaries of the same companies and the like.

A professor starts a lecture by posing a question about problems inside the company which could have caused the conflict or another situation at the company which requires extraordinary solution. The aim of professor who acts as facilitator is to get at least 6-7 suggestions from audience which could be later elaborated 
further. Here students are encouraged to express their opinions, explain why they one or another suggest formulation. Suggestions are written by the teaching professor on a blackboard for further analysis. This case teaching moment is extremely important as actually is a powerful mean of student leadership abilities development. Students are encouraged to put themselves into shoos of CEO and make a list of possible problems. Let us recall that such analysis has been already practiced in groups prior a lecture. Let us put a stages of case analysis in structured way in order to see all the sequence:

- Making an extensive list of possible problems, which are embedded in the analyzed company

- Revising critically an extensive list and concentrating on estimated 6-7 problems

- Foreseeing and discussing ways of solving of the problems and consequences of their solution (Figure 1)

Making an list of possible problems
Revising critically and

concentrating on

particular problems
Ways of problem solving and expected consequences

Fig. 1. The first three stages of case analysis Source: Own results

Indicated problems usually have multiple alternative ways, or tools set for their solving with respective consequences. Therefore, each way has to be discussed and consequences of the chosen toolset realized in full scale (Figure 2).

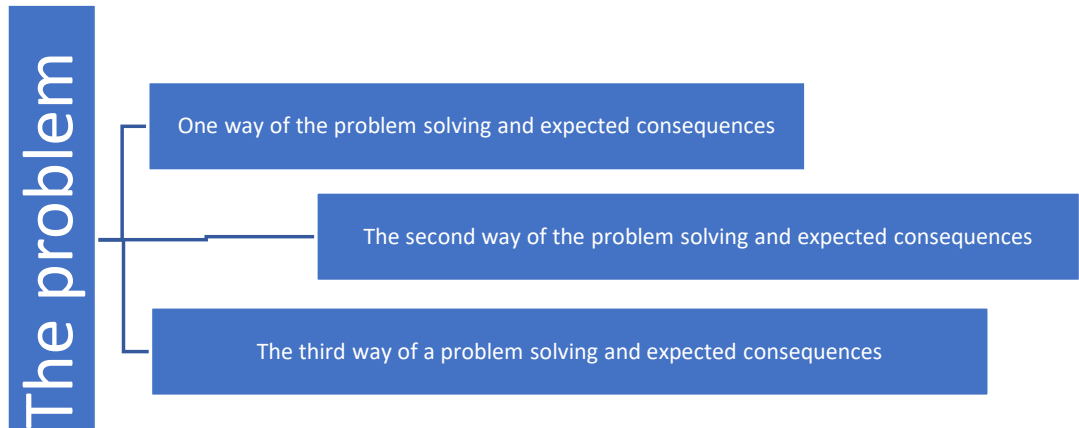

Fig. 2. Considering ways of the problem solving Source: Own results

The following steps of the case analysis are:

- Making an action plan for solving the problems in longer run

- Making a decision how to deal with arisen problem in a short run, i.e "tomorrow".

The last two stages of case study analysis "making an action plan for solving the problems in longer run" and "making a decision how to deal with arisen problems "tomorrow" requires additional explanation. Recall, that a business case used for educational purposes has to finish at the moment, when a company encounters a problem, which has to be solved without delay. Such urgent problems usually are expressed through extreme situations, e.g. open conflicts, rude infringements of company's performance etc. The task of top management is twofold: one the one hand thorough analysis has to be done, in order to reveal causes of those problems in order to neutralize them, and, on the other hand, an immediate decision has to be made in order "to put fire" right now. "Putting fire right now" does not eradicate problems embedded in the company itself, therefore it is nerveless very important for smoothing companies' performance in the nearest future. Those immediate decisions usually are impulsive and not that well thought through as company's transformation strategies born as result of thorough analysis. Leadership style is the factor which affects the immediate decision. Students, which obtain case study experience become rather well prepared for real life challenges, therefore case study teaching provides a lot of opportunities to develop leadership abilities and therefore can't be overestimated.

Despite development of future business leader cannot be imagined without case studies, the limitations of this methods must be discussed as well. There are a lot of literature devoted both to advantages 
and disadvantages of case studies use (e.g. Vissak 2010). We will provide our authentic insights based on extensive personal teaching experience. Hence, the following limitations have to be indicated:

- $\quad$ Estimated 10-20 percent of students do not accept case studies method at all. It is especially applied to students, which study business as additional discipline, while the main study area is non-social studies area, e.g. engineering. Intuition is lack of social studies result in lack of abilities to make decisions in uncertain situations

- $\quad$ Case studies, which require specific knowledge in finance, knowledge in accountancy and overall economic education is being resolved with much less enthusiasm and mutual discussion if to compare with cases on organizational culture, human resource management etc. It shows that financial and economic knowledge appears to be rather frequently weak (Tkacova et al. 2018) and therefore difficult to apply.

\section{Conclusions}

Teaching of business case studies appears to be absolutely compulsory in contemporary universities. Thence, in order for the teaching to lead to fostering the creation of effective business leaders the case studies used in the study process have to be carefully selected and contain the methodology that should be carefully crafted and designed.

In addition, it seems important that these case studies have to be distinguished from artificially simulated business tasks. Case studies require preparation of students, which has to be done before case study lecture. One can clearly see that universal transformation of students into clients of universities threaten to hinder quality of business education, especially in cases when students are allowed to participate in case study teaching without a priori preparation.

Therefore, using of the case studies in teaching is a powerful tool for fostering of students' leadership abilities. In the same time, one has to acknowledge that limitations of case studies used in teaching cannot be ignored and thence should be carefully thought over, prepared and executed.

\section{References}

Al-Kahtani N S (2018). Perception of private telecom employees towards unfair HRM practices: an empirical investigation. Entrepreneurship and Sustainability Issues 5(4): 957-966. doi: 10.9770/jesi.2018.5.4(18)

Białowąs P (2018) Enterprise restructuring: a quality management paradigm. Czech Journal of Social Sciences, Business and Economics 7(1):24-28. doi: 10.24984/cjssbe.2018.7.1.3

Bogdanović M, Vetráková M, Filip S (2018). Dark triad characteristics between economics \& business students in Croatia \& Slovakia: what can be expected from the future employees? Entrepreneurship and Sustainability Issues 5(4): 967-991. doi:10.9770/jesi.2018.5.4(19)

Č́belková I, Abrhám J, Strielkowski W (2015) Factors influencing job satisfaction in post-transition economies: the case of the Czech Republic. International Journal of Occupational Safety and Ergonomics 21(4):448-456. doi: 10.1080/10803548.2015.1073007

Durglishvili N (2017) Labour market perspectives for the university graduates in Georgia. International Economics Letters 6:1-6. doi: 10.24984/iel.2017.6.1

Kalyugina S, Strielkowski W, Ushvitsky L, Astachova E (2015) Sustainable and secure development: facet of personal financial issues. Journal of Security \& Sustainability Issues 5(2):297-304. doi: 10.9770/jssi.2015.5.2(14)

Koudelková P, Svobodová P (2014) Knowledge creation \& sharing as essential determinants of SMEs innovation. International Economics Letters 3(1): 12-20. doi: 10.24984/iel.2014.3.1.3

Kubeš V, Rančák J (2018) Sustainability of organization performance via management techniques. Entrepreneurship and Sustainability Issues 5(4): 1031-1042. doi: 10.9770/jesi.2018.5.4(23)

Mikhaylov AS (2018) Socio-spatial dynamics, networks and modelling of regional milieu. Entrepreneurship and Sustainability Issues 5(4): 1020-1030. doi: 10.9770/jesi.2018.5.4(22) 
Naushad M, Faridi M R, Syed A M (2018) Economic development of community by entrepreneurship: an investigation of the entrepreneurial intent and the institutional support to the local community in Al-Kharj region. Entrepreneurship and Sustainability Issues 5(4): 899-913. doi:10.9770/jesi.2018.5.4(14)

Naushad M. (2018) A study on the antecedents of entrepreneurial intentions among Saudi students. Entrepreneurship and Sustainability Issues 5(3): 600-617. doi:10.9770/jesi.2018.5.3(14)

Orlova L, Gagarinskaya G, Gorbunova Y, Kalmykova O (2018) Start-ups in the field of social and economic development of the region: a cognitive model. Entrepreneurship and Sustainability Issues 5(4):795811. doi:10.9770/jesi.2018.5.4(7)

Plenkina V, Andronova I, Deberdieva E, Lenkova O, Osinovskaya I (2018). Specifics of strategic managerial decisions-making in Russian oil companies. Entrepreneurship and Sustainability Issues 5(4): 858874. doi:10.9770/jesi.2018.5.4(11)

Ragulina Y V, Semenova E I, Zueva I A, Kletskova EV, Belkina E N (2018) Perspectives of solving the problems of regional development with the help of new internet technologies. Entrepreneurship and Sustainability Issues 5(4): 890-898. doi:10.9770/jesi.2018.5.4(13)

Shvetsova OA, Rodionova EA, Epstein MZ (2018). Evaluation of investment projects under uncertainty: multi-criteria approach using interval data. Entrepreneurship and Sustainability Issues 5(4):914928. doi:10.9770/jesi.2018.5.4(15)

Strielkowski W, Rausser G (2013) International Labour Migration and Structural Channels: A Case Study of Ukrainian Working Migrants in the Czech Republic. Ekonomicky Casopis 61(10):1034-1052.

Strielkowski W, Tumanyan Y, Kalyugina S (2016) Labour Market Inclusion of International Protection Applicants and Beneficiaries. Economics \& Sociology 9(2):293-302. doi: 10.14254/2071-789X.2016/9-2/20

Strielkowski W (2018) A postdoc's purpose. Science 360(6384):27-27. doi: 10.1126/science.aat6008

Tkacova A, Kubak M, Androniceanu A, Tvaronavičienė M, Huculova E (2018) Financial literacy of students in chosen universities - research platform for regulatory processes of educational system in Slovakia. E $+\mathrm{M}$. Economics and Management 21(1): 175-190 doi:10.15240/tul/001/2018-1-012

Tvaronavičienė M. (2018). Preconditions of sustainable entrepreneurship: estimating of Brexit scenarios' impact on macroeconomic environment. Polish Journal of Management Studies 17 (2): 222-234 doi:10.17512/pjms.2018.17.2.19

Vissak T (2010) Recommendations for Using the Case Study Method in International Business Research. The Qualitative Report 15(2):370-388.

Yin RK (2006) Case Study Methods. In J. L. Green, G. Camilli, \& P. B. Elmore (Eds.), Handbook of complementary methods in education research (pp. 111-122). Mahwah, NJ, US: Lawrence Erlbaum Associates Publishers.

Zielińska A (2016) Information is a market products and information markets. Czech Journal of Social Sciences, Business and Economics 5(4):31-38. doi: 10.24984/cjssbe.2016.5.4.4 